\title{
Evaluating Responses in Complex Adaptive Systems: Insights on Water Management from the Southern African Millennium Ecosystem Assessment (SAfMA)
}

\author{
$\underline{\text { Erin Bohensky }}^{1}$ and Timothy Lynam ${ }^{2}$
}

\begin{abstract}
Ecosystem services are embedded in complex adaptive systems. These systems are riddled with nonlinearities, uncertainties, and surprises, and are made increasingly complex by the many human responses to problems or changes arising within them. In this paper we attempt to determine whether there are certain factors that characterize effective responses in complex systems. We construct a framework for response evaluation with three interconnected scopes or spatial and temporal domains: the scope of an impact, the scope of the awareness of the impact, and the scope of the power or influence to respond. Drawing from the experience of the Southern African Millennium Ecosystem Assessment (SAfMA), we explore the applicability of this framework to the example of water management in southern Africa, where an ongoing paradigm shift in some areas has enabled a transition from supply-side to demand-side responses and the creation of new institutions to manage water across scales. We suggest that the most effective responses exhibit congruence between the impact, awareness, and power scopes; distribute impacts across space and time; expand response options; enhance social memory; and depend on power-distributing mechanisms. We conclude by stressing the need for sufficient flexibility to adapt responses to the specific, ever-evolving contexts in which they are implemented. Although our discussion focuses on water in southern Africa, we believe that the framework has broad applicability to a range of complex systems and places.
\end{abstract}

Key Words: responses; complex adaptive systems; ecosystem services; southern Africa; watermanagement; impact; awareness; power

\section{INTRODUCTION}

Ecosystems, the services they provide, and the people who use and manage them comprise complex adaptive systems. Because complex systems are inherently nonlinear, variable, and uncertain, they are seldom predictable; if anything, surprise is the norm (Costanza et al. 1993, Gunderson and Holling 2002). Part of their complexity lies in the fact that human responses to different situations are constantly occurring across different scales and levels of organization, playing out in multiple, uncoordinated, improvisational theatres in which the actors are never quite sure what will happen next. Because of the great uncertainties in complex systems, we cannot predict the full range of a response's implications. All responses are, therefore, experiments.

This does not mean that the way complex systems work is beyond human comprehension. Complexity often emerges from simple rules (Lee 1993). Within the complex couplings of people and nature, experimentation, adaptation, and co-evolution have taken place for as long as humans have existed. A wealth of information exists from the long history of human experience with ecosystem change that can contribute to current understanding and ultimately foster sustainability.

In this paper, we seek an answer to the following question: What factors characterize effective responses in complex adaptive systems? "Responses" are behavioral, institutional, or technical adaptations 
that people make to deal with, or in anticipation of, problems or changes in complex systems. Although ecosystems also respond to change, we limit our discussion to human responses.

The definition of an "effective" response in a complex adaptive system also needs some clarification. It is naïve to suggest that effectiveness means achieving objectives. For example, dams are often effective in stabilizing river flows and providing hydropower, but they have severely undermined human livelihoods and the downstream delivery of ecosystem services (World Commission on Dams 2000a). In essence, these responses have yielded benefits to some components of the system at a significant cost to other components. In the context of this paper, we use the term "effective" to mean responses that maintain a system's social and ecological resilience. Resilience is used here to refer to the amount of change a system can withstand while retaining its structure and the variables and processes that control its behavior (Holling and Gunderson 2002). Resilient systems tend to be selforganizing as opposed to controlled by external forces, and can build the capacity to learn and adapt (Carpenter et al. 2001).

We present a simple framework for evaluating responses and explore it using the experiences and information generated by SAfMA, the southern African component of the Millennium Ecosystem Assessment. We focus our evaluation on responses for managing water in southern Africa, where recent changes in the water sector make it a particularly compelling case, although we believe that the same framework can be applied to other problems that involve complex systems of people and nature.

\section{RESPONSES IN THE MILLENNIUM ECOSYSTEM ASSESSMENT}

The Millennium Ecosystem Assessment is a 4-yr international process intended to provide decision makers with scientific information about the relationships between ecosystems and human wellbeing. It marks a departure from other global assessments in several ways: it is multiscale in space and time; integrated in that it involves ecologists, social scientists, and economists; and user-driven, serving a range of information needs, from those of local communities to international environmental conventions. Central to the design of the Millennium Ecosystem Assessment is a common conceptual framework (Millennium Ecosystem Assessment 2003) that describes the relationships between ecosystems and their services, human wellbeing and poverty reduction, and direct and indirect drivers of ecosystem change. Within the framework of the Millennium Ecosystem Assessment there are opportunities for responses, including strategies and interventions that can halt, reverse, or otherwise change these relationships. A critical aspect of the work of the Millennium Ecosystem Assessment is the identification of features of responses that cause them to succeed or fail, information that will eventually be useful for decision makers choosing from among different response options.

The Southern African Millennium Ecosystem Assessment (SAfMA) is one of approximately 30 subglobal assessments linked to the Millennium Ecosystem Assessment. Using the framework of the Millennium Ecosystem Assessment, SAfMA evaluated southern African ecosystems and the ways in which they support human societies. SAfMA consists of the following partially nested assessment components: a regional assessment of 19 countries of mainland Africa south of the equator; two river basins, the Gariep and the Zambezi; four local assessments located within the Gariep basin; and a local assessment of the Gorongosa-Marromeu, Mozambique, region in the Zambezi basin (Fig. 1).

The SAfMA teams generally used two approaches to assess responses: at coarser scales, e.g., regional and river basin, we reviewed past and present responses, and at local scales we used interactive processes involving stakeholders to elicit information about the responses used or likely to be used in alternative future worlds depicted by scenarios. Although many of us had expected response evaluation to be the simplest component of the conceptual framework, we had difficulty distilling clear messages from the information available about what makes a response work.

We observed that responses may be proactive, that is, people expect an impact to occur and begin responding before the impact happens. Many policies fall into this category. Other responses are reactive, or those in which people begin responding only after an impact happens or is perceived, such as when a herder decides to move in response to shifts in rainfall. If people cannot affect drivers of change, they are more likely to adopt reactive 
Fig. 1. The Southern African Millennium Ecosystem Assessment study area and its nested, multiscale design. Note that the actual Gariep basin (indicated by a dashed line) extends beyond the area assessed (Biggs et al. 2004).

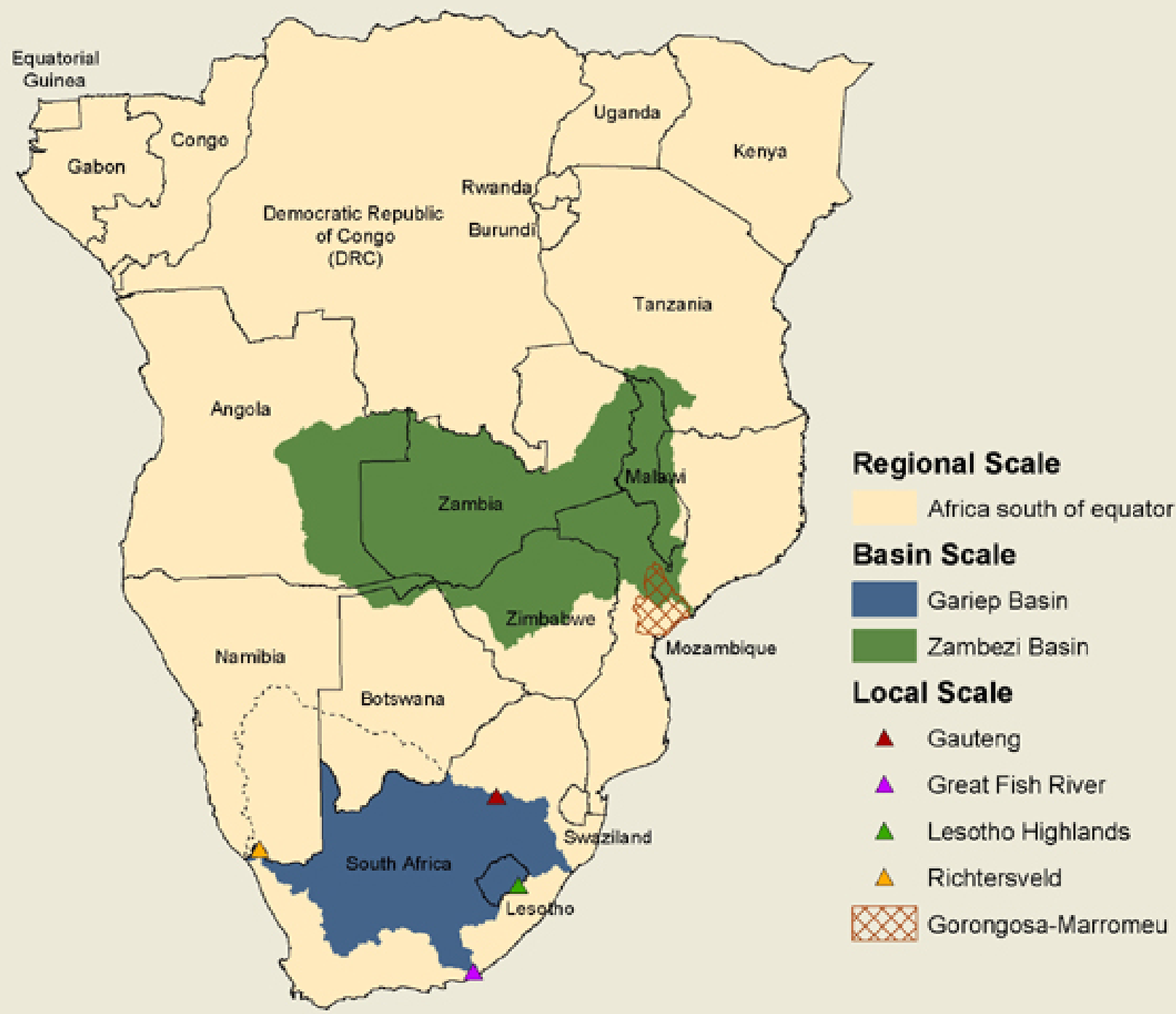

response options. We focus on proactive responses in this paper. We believe that many of the suggestions we make will also hold true for reactive responses, but do not specifically explore them.

We found it helpful to develop our own simple framework to address the focal question of what makes a response effective, which we then applied to the real-world example of water management based on the SAfMA experience. Below we describe the framework, demonstrate its utility by evaluating responses used to manage water in two southern African river basins, and suggest simple guidelines for designing effective responses. 


\section{A FRAMEWORK FOR RESPONSE EVALUATION}

We construct our framework for response evaluation with three interconnected components, which we call scopes of impact, awareness, and power. The impact scope is the spatial and temporal domain in which an impact occurs: who or what is impacted, where, when, and for how long. The same impact situation can affect different groups or locations differently, either in space, in time, or both. Climate change, for example, is expected to make some areas of southern Africa better suited to grain production and other areas worse (Jones and Thornton 2003).

The second component of our framework for response evaluation is awareness. People respond to actual or perceived changes in some matter of consequence to them. They will not deliberately respond to a change unless they are aware of it. It must first register on their conscious or unconscious minds. We differentiate between two major elements of awareness. The first is awareness of the consequences or impacts of a change. This often encompasses awareness of a state, such as the amount of water in a stream, or of a trend, such as a decrease in this amount over time. The second element is an awareness of the direct and indirect drivers of the observed or expected change. Unless people are aware that increased anthropogenic $\mathrm{CO}_{2}$ emissions cause changes in the global temperature, and that changes in temperature can change ecosystems that they depend on, they cannot understand why certain preventive actions are required to curtail these emissions. In both instances, we use the term awareness to reflect a reasonably true state of knowledge characterized by useful degrees of accuracy and precision. Inaccurate or imprecise awareness by this definition has little utility and is therefore at least as bad as being unaware, and possibly worse. Awareness in a complex system implies learning. As the system changes, new drivers and conditions emerge. Awareness must be sufficiently flexible to incorporate these changes through learning.

People will often seek to capture the benefits of a response while transferring the costs or disservices elsewhere in time or space. For example, a government's decision to construct a dam to capture the benefits of cheap hydroelectric power transfers ecosystem disservices, such as reduced fisheries production or reduced alluvial deposition for riverbank agriculture, and consequent disruption of livelihood systems to people living downstream or to future generations. Awareness is therefore a broader concept than we have initially portrayed it. For responses to be effective, there must also be an awareness of cross-sectoral and cross-scale, i.e., spatial and temporal, trade-offs. This requires a great deal of knowledge about, and sensitivity to, a response's implications for all sectors of society.

The third component of our framework is power. People may be aware of an impact such as reduced streamflow and both its direct causes, e.g., a decrease in rainfall, and its indirect causes, e.g., anthropogenic climate change. However, they may not be able to alter these factors. For example, responses identified by rural villagers in central Mozambique to two scenarios of the future were all reactive (Lynam et al. 2004). This is a key observation. Poor people perceive themselves to be largely powerless to influence the major processes that govern their livelihoods, and indeed they often are. Powerlessness is not unique to the poor, however; affluent people may be able to do little more than rural villagers to affect climatic processes. The resilience of livelihoods is enhanced by having a wide set of response options, both reactive and proactive. Choice counts, and power expands choice.

Power, like impacts and awareness, is seldom symmetrically distributed in time or space or among actors. Because power tends to accumulate upward through hierarchical structures, often the only way that people can influence large-scale causal processes is indirectly through political or economic mechanisms that convey cumulative expressions of individual wishes, such as elections or markets. These mechanisms can be slow or dominated by individuals and societies elsewhere with different problems and needs. Responses are often lagged, such that their effects are only felt long after the causal factors have been alleviated. This can result in system over- or undershoots as lagged responses try to correct historical deviations from desirable states. The asymmetry of power has an important implication: there will always be trade-offs between the different needs or desires of different social groups. Mechanisms that influence power distribute benefits and costs and thus define winners and losers. Future generations are often the losers (and sometimes the winners) by default, because they have no control over current responses. 
Fig. 2. (A) Impact, awareness, and power scopes are nearly congruent. (B) Impact, awareness, and power scopes are highly incongruent.

a)
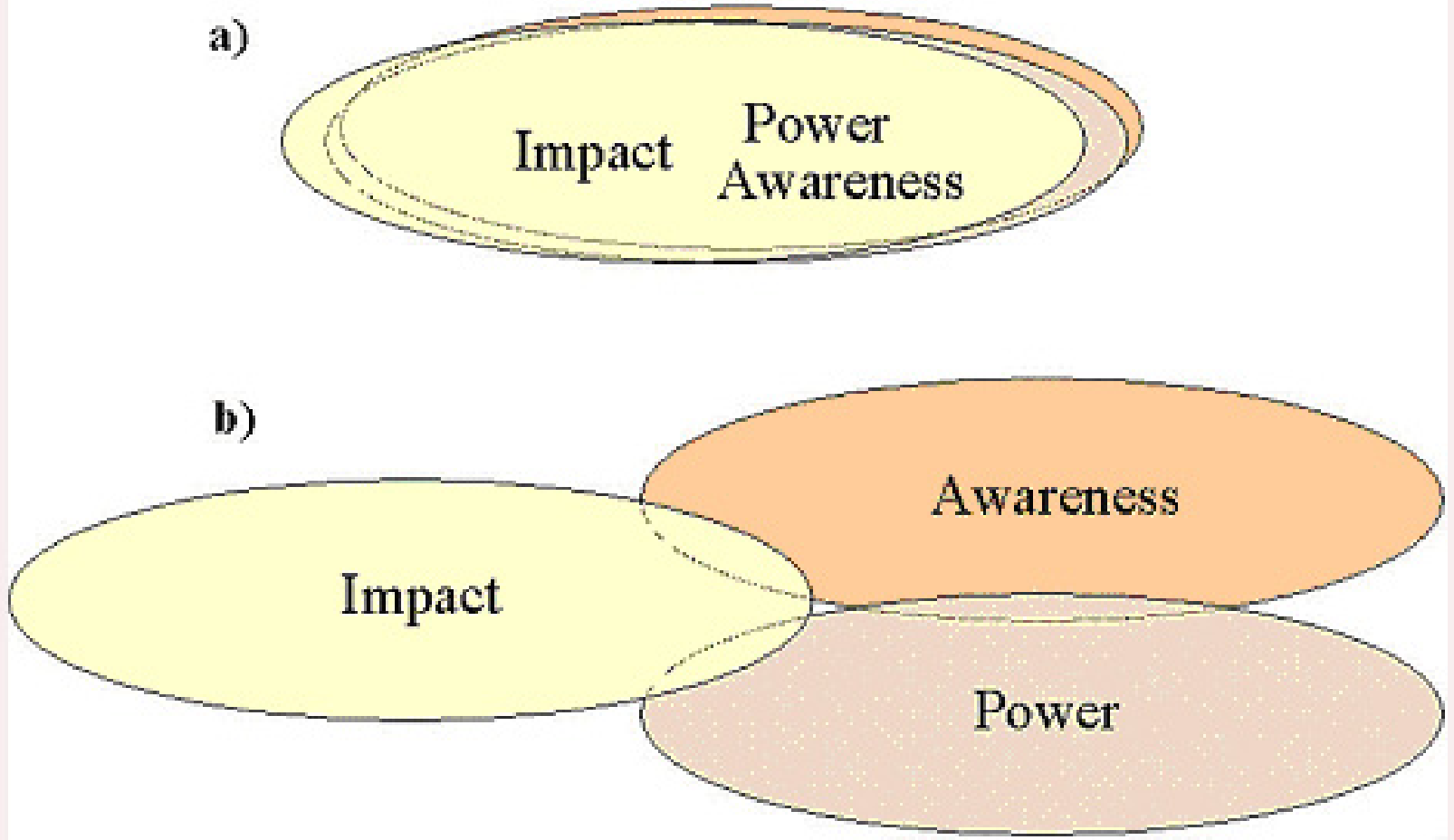
We suggest that when the people affected are fully aware of the consequences and causes of a change and have the power to alter the processes driving those changes, they have a good chance of selecting and implementing effective responses. We refer to this situation as congruence, or overlap, among the impact, awareness, and power scopes (Fig. 2A). When these components are incongruent or nonoverlapping (Fig. 2B), it seems to us that the chances of effective responses being identified and implemented are reduced.

Identifying an effective response to a problem in a complex adaptive system can be difficult because impacts, awareness, and power are dynamic. Impacts are not uniformly and simultaneously experienced everywhere by everyone, and responses will emerge at different scales in space and time. A flood wave that inundates the Zambezi Valley is first experienced in the upper reaches, then the lower, and is then felt indirectly by the adjacent communities who absorb the refugees and perhaps finally by the national government when budget lines are shifted to relief efforts. Local people alter their behavior immediately by moving from the flood zone. District, provincial, national, and international administrators and relief agencies mobilize resources to support the affected people.

The impact continues, but over time becomes more like a ripple from a stone dropped in a pond. Once the immediate needs have been addressed with reactive responses, policy makers begin to develop proactive responses, such as the design of new monitoring systems and agencies. Downstream, people seek assistance to rebuild the houses and livelihood systems destroyed by the flood. New plans are formulated to improve dam management so that the flood cannot happen again, new flood early-warning systems are installed, and regional cooperative linkages are improved to better coordinate flood releases. There is new learning, both social and ecological, e.g., about new channels gouged from the river bed, resulting in a new awareness that institutions quickly try to capture. Then slowly the impact and its memories begin to fade as other priorities and concerns take center stage. Just as the impact ebbs and flows spatially and temporally in the wake of the flood event, so too do awareness and power. Power generally shifts much more slowly, if at all. As new agencies for cooperation are formed, new powers are created or old ones transformed. With each response, a new configuration of impacts, awareness, and power takes shape. The stage is set for another performance.

In what follows we apply the framework in an exploration of historical and current responses to manage water in the Gariep and Zambezi River basins, and seek lessons from this framework in understanding responses in complex adaptive systems.

\section{WATER MANAGEMENT IN SOUTHERN AFRICA: RESPONSE THEATRE IN PROGRESS}

Southern Africa is characterized by high climatic variability, uneven spatial and temporal distribution of runoff, and a history of attempts, with varying success, to compensate for an unpredictable water supply. Water issues in this region are now being cast in a new light, illuminating the essential challenge to balance the preservation of ecological integrity with the achievement of social and economic development objectives. Several countries are reforming their water laws and are increasingly decentralizing management or forming new institutions, often across national boundaries. However, this shift has not been universal, and water-related problems are expected to persist in some areas, especially where competition for water is fierce and institutions are weak. The result is a temporal and spatial mosaic of water management systems that presents a unique case for evaluating responses across various temporal and spatial scales and socioeconomic conditions.

The two river basins that the Southern African Millennium Ecosystem Assessment (SAfMA) evaluated are different pieces of this mosaic (Table 1). The Gariep is water-stressed (Falkenmark and Widstrand 1992), with the small mountainous region of Lesotho and the South African Drakensberg highlands contributing significantly to the basin's runoff through a series of ambitious diversions of water to the major South African demand centers. In contrast, the Zambezi is endowed with a relative abundance of water. The Gariep basin contains one of the greatest concentrations of wealth on the African continent, Gauteng Province, which includes the Johannesburg and Pretoria metropolitan areas, whereas the eight nations that share the Zambezi are among the poorest in the world. Human well-being as reflected 
Table 1. Characteristics of the Gariep (M. D. Watson, personal communication) and Zambezi (Snaddon et al. 1999, area and mean annual runoff; Revenga et al. 1998, per capita water availability) basins. Human development index figures are from UNDP (2003).

\begin{tabular}{|c|c|c|c|c|c|}
\hline & Area $\left(\mathrm{km}^{2}\right)$ & Countries sharing basin & $\begin{array}{l}\text { Mean annual } \\
\text { runoff }\left(\mathrm{m}^{3} / \mathrm{yr} x\right. \\
\left.10^{6}\right)\end{array}$ & $\begin{array}{l}\text { Per capita water } \\
\text { availability }\left(\mathrm{m}^{3} \cdot\right. \\
\left.\text { person }^{-1} \cdot \mathrm{yr}^{-1}\right)\end{array}$ & $\begin{array}{l}\text { Human development } \\
\text { index }\end{array}$ \\
\hline Gariep & $1,039,266$ & $\begin{array}{l}\text { Botswana, Lesotho, } \\
\text { Namibia, South Africa }\end{array}$ & 15,957 & 1125 & $\begin{array}{l}\text { All medium- } \\
\text { development nations } \\
\text { (rank 111th to } 137 \text { th) }\end{array}$ \\
\hline Zambezi & $1,234,000$ & $\begin{array}{l}\text { Angola, Botswana, } \\
\text { Malawi, Mozambique, } \\
\text { Namibia, Tanzania, } \\
\text { Zambia, Zimbabwe }\end{array}$ & 110,000 & $>10,000$ & $\begin{array}{l}\text { All low-development } \\
\text { nations except Botswana, } \\
\text { Namibia, Zimbabwe } \\
\text { (rank 124th to 170th) }\end{array}$ \\
\hline
\end{tabular}

by the human development index (UNDP 2003) is on average higher in the Gariep than the Zambezi.

These characteristics are indicative of the conditions that enable and the constraints that bind possible responses, i.e., the realities on the ground at a given moment that determine whether or not people can or will adopt responses that are sustainable. Each societal response to the problem of water availability can generally be described as falling into one of three categories: supply augmentation, conservation, or allocation (Molle 2003). Supplies are augmented, for example, by constructing storage dams and reservoirs or diverting water from within or across basin boundaries. Conservation strives for increased efficiency in the use of existing water resources. Allocation refers to the redistribution of water from one user or sector to another to alleviate some of the total pressure on water resources. As a consequence of the actual or perceived decreasing abundance of water resources over time, initial responses to water management are typically supply-side strategies involving augmentation, followed, if possible, by a shift to demand-side strategies that focus on conservation and allocation.

The development of water resources in the Gariep basin exemplifies the typical progression from supply-side to demand-side responses. In contrast, the Zambezi basin, where there is more water and less demand for it, has not undergone the same progression, although it still could. Whether a river basin progresses through this trajectory of approaches to dealing with water problems depends on what Ohlsson and Turton (2000) call a "turning of the screw" between a first-order scarcity of water and a second-order scarcity of the social resources required to successfully adapt to the first-order scarcity. Within the Gariep basin, first-order scarcity is high, but second-order scarcity is relatively low because of the management capacity that exists in South Africa, in which most of the basin lies. In the Zambezi, first-order scarcity is low but second-order scarcity is fairly high because of limited social resources and capacity to use a range of responses to address water-related problems.

Despite these differences between the Gariep and Zambezi, the responses selected to manage water in these two basins were initially similar; they have only begun to diverge more recently.

\section{The "get more water" era}

Until the mid-1900s, the focus of water management in most southern African countries, apart from securing the relatively small amounts needed for municipal and domestic use, was on increasing or stabilizing supplies for irrigation. South Africa's shift in the middle of the last century from an irrigation-centered water policy to one based on a more diversified economy is reflected in its passage of its 1956 Water Act, which repealed its Irrigation and Conservation Act of 1912. Although irrigation continues to consume most of the total available runoff, currently more than $60 \%$ in the Gariep basin, 
in South Africa the contribution of agriculture to the gross national product is small (less than 5\%) relative to the mining, manufacturing, and services sectors.

For the purposes of this paper, we unite these two phases into a single era in which "getting more water" (Dent 2000) was of primary concern and was addressed through supply-side responses that tended to favor the agricultural and, later, the industrial sectors. In South Africa, this was achieved through a centralized system of management, informed by a science that resided largely in government departments, and through laws that put water-related decision making in the hands of the state and private landowners. Throughout the region, variable and unpredictable river flows were dealt with largely through technical responses, leaving a legacy of imposing structures across the landscape as physical evidence of the prevailing mindset of the time.

In the Gariep basin, the Orange River Development Project (ORDP) commenced in 1962 and included South Africa's two largest dams and a major interbasin transfer scheme. Built primarily to secure water supplies for the commercial agricultural sector, the power base of South Africa's then-ruling National Party, the ORDP was also intended to strengthen the party's apartheid regime as it faced increasing internal and international resistance. The Lesotho Highlands Water Project (LHWP), a joint undertaking by South Africa and Lesotho to supply water to the former and electricity to the latter, is the most recent of the region's major dam projects. Envisioned when initiated in 1986 to have five dams, which would have made it second in size only to China's Three Gorges, the LHWP was eventually scaled down considerably, at least partly because of the realization that initial water demand forecasts were too high and supplies too low (Klasen 2002). In the Zambezi, the World Bank-backed Kariba dam was completed in 1959 on the border between Zambia (then Northern Rhodesia) and Zimbabwe (then Southern Rhodesia) to supply power to the region's growing copper mines and manufacturing industries after World War II. Construction on the Cahora Bassa dam began in the 1960s; when completed in 1975, it enabled the Portuguese colonial government in Mozambique to produce hydropower for sale to South Africa.

This focus on augmenting water supplies or services such as hydropower succeeded in improving human well-being for some members of society. Improvements in the Gariep included significant economic and social benefits in the form of increased water supply, agricultural production, flood protection, hydropower, and employment (World Commission on Dams 2000b). In the Zambezi, the Kariba dam encouraged tourism to the lake and a significant kapenta fishery, both providing employment. Reliance on coal-fired electricity was alleviated, and the cost of electricity in the area served by the Kariba and Kafue dams decreased by about 30\% between 1961 and 1977, even as the average price for other commodities and services rose by more than $75 \%$ during the same period (Soils Incorporated 2000).

However, these responses also had several serious negative consequences. These include the social impacts such responses had on communities, especially but not exclusively poor ones. In particular, tens of thousands of individuals were displaced or resettled to more marginal lands without consultation and with little or no compensation (Isaacman and Sneddon 2000, Soils Incorporated 2000, Thabane 2000, World Commission on Dams 2000b). This was particularly acute in projects executed under colonial or apartheid regimes because of the social and political acceptability of relocating people as the state saw necessary to achieve project objectives. Because such practices had become internationally unpopular by the time the LHWP was built, affected people were compensated for losses in a process that has begun to bring the realities of some of the social and environmental impacts, typically externalized, of large dam projects to bear on their overall economic viability. Despite these major investments in water resources, the distribution of benefits has remained highly skewed, accruing more to commercial farmers, distant cities, and tourists than to the residents in the vicinities of these projects (Soils Incorporated 2000). Where rural people in these basins have lacked access to formal water services, they have relied on direct withdrawals from rivers for domestic use and livestock watering, putting undue pressure on rivers and riparian zones (Motteux 2002).

An additional problem with responses aimed at augmenting water supplies in the southern African region, as elsewhere, is that their potential effects on ecosystems were ignored in the planning and implementation processes. This resulted some time later in ecosystem degradation and transformation 
that reached disastrous proportions in some places. Along the lower Gariep River, a pest blackfly (Simulium chutteri) infestation erupted after the flow regime was changed by the ORDP (Chutter et al. 1996), costing the agriculture sector an annual $88 \times 10^{6}$ South African Rands or $14.7 \times 10^{6} 1998$ U. S. dollars in livestock productivity losses and another $2 \times 10^{6}$ South African Rands or 1998 U.S. $\$ 330,000$ in annual control costs (World Commission on Dams 2000b). The potential impacts of the project on water quality were overlooked at the onset despite warnings, so that planners were surprised when salinity levels suddenly increased after water began traveling through the Orange-Fish tunnel (Herold 1992). In the Zambezi, the Kariba and Cahora Bassa dams have had deleterious effects on downstream ecosystem services. These include morphological changes in the river and floodplain, disrupted sediment and nutrient flows, widespread encroachment of woody savanna onto the herbaceous floodplain in the Marromeu wetland complex, a $40 \%$ loss of mangroves, and coastal erosion. Wetlands have been disconnected from the main channel of the Zambezi, disturbing bird and fish habitat, with a $60 \%$ reduction in prawn catch rates attributed to the decline in runoff between 1978 and 1995 (Davies et al. 2000).

The planning of large dams during this era was often flawed because of inadequate public participation and inappropriate project timelines. The political expediency of the ORDP's authorization made detailed planning impossible and even cursory impact assessments implausible. One result of its hasty implementation was that the project experienced unanticipated delays and cost three times more than its initial budget, rising from a projected 1998 U.S. $\$ 571.3 \times 10^{6}$ in $1962-1963$ to U.S. \$2313.7 x 106 when completed (World Commission on Dams 2000b). In some projects, the laws and procedures in existence at the project's inception had changed, sometimes radically, by the time of its completion. In the LHWP, an environmental impact assessment for downstream effects was only conducted retroactively after the first dam was in operation (Lesotho Highlands Development Authority 2002).

Finally, the focus on supply augmentation created an illusion of abundant water resources and obscured the signs that the natural limits of the water supply were being rapidly approached, even as droughts devastated parts of southern Africa during the 1980s and 1990s. In 1995, such a drought led water managers in Gauteng Province to restrict water use unless major rain events occurred during the following summer. The rains came, and restrictions were lifted. However, by implementing a very localized, short-sighted response, a potential signal to curb water losses was ignored, and an opportunity to better manage water demand was lost (Snaddon et al. 1998).

Cumulative storage-dam capacity in South Africa increased steadily from 1900 to 1975 and then increased sharply between 1975 and 1990 (Fig. 3), appropriating an ever larger share of the total freshwater supply. Only in the 1990s did growth slow significantly as a result of the saturation of available dam sites, along with the increasing acceptance by water managers that there was little water left to allocate and that the actual cost:benefit ratios of large dam projects were rarely as low as originally projected.

The "get more water" era was characterized by highcost technical responses to problems of water scarcity in the Gariep and the supply of cheap energy in the Zambezi, and had similar effects despite the different characteristics of these river basins. These responses emerged in the age of "control thinking," in which it was believed that everything could be effectively controlled to achieve clearly defined objectives. The world was seen to be a linear, reducible system that could be fully understood, but, in fact, awareness was highly limited in that the impacts of these responses on livelihoods and ecosystems were underestimated or simply ignored. Certain individuals recognized these problems, of course, but were unable to motivate the majority to act. Impact, awareness, and power were seldom, if ever, congruent. The result was that the water management responses of the time often created new problems by attempting to solve old ones without contemplating their possible effects across space and time.

We should not expect, in a complex system, to fully understand system functioning or to be able to predict system behavior with meaningful certainty. Responses must be designed to take this into account. Even though we can never have enough data (Johannes 1998), awareness needs to be distributed across all scales and sectors of the system. In South Africa, the state's control of waterrelated research effectively obliterated the potential 
Fig. 3. Water supply augmentation, illustrated by cumulative storage-dam capacity in South Africa from pre-1900 until 1997 (Aquatic Resource Management for Local Communities 1999).

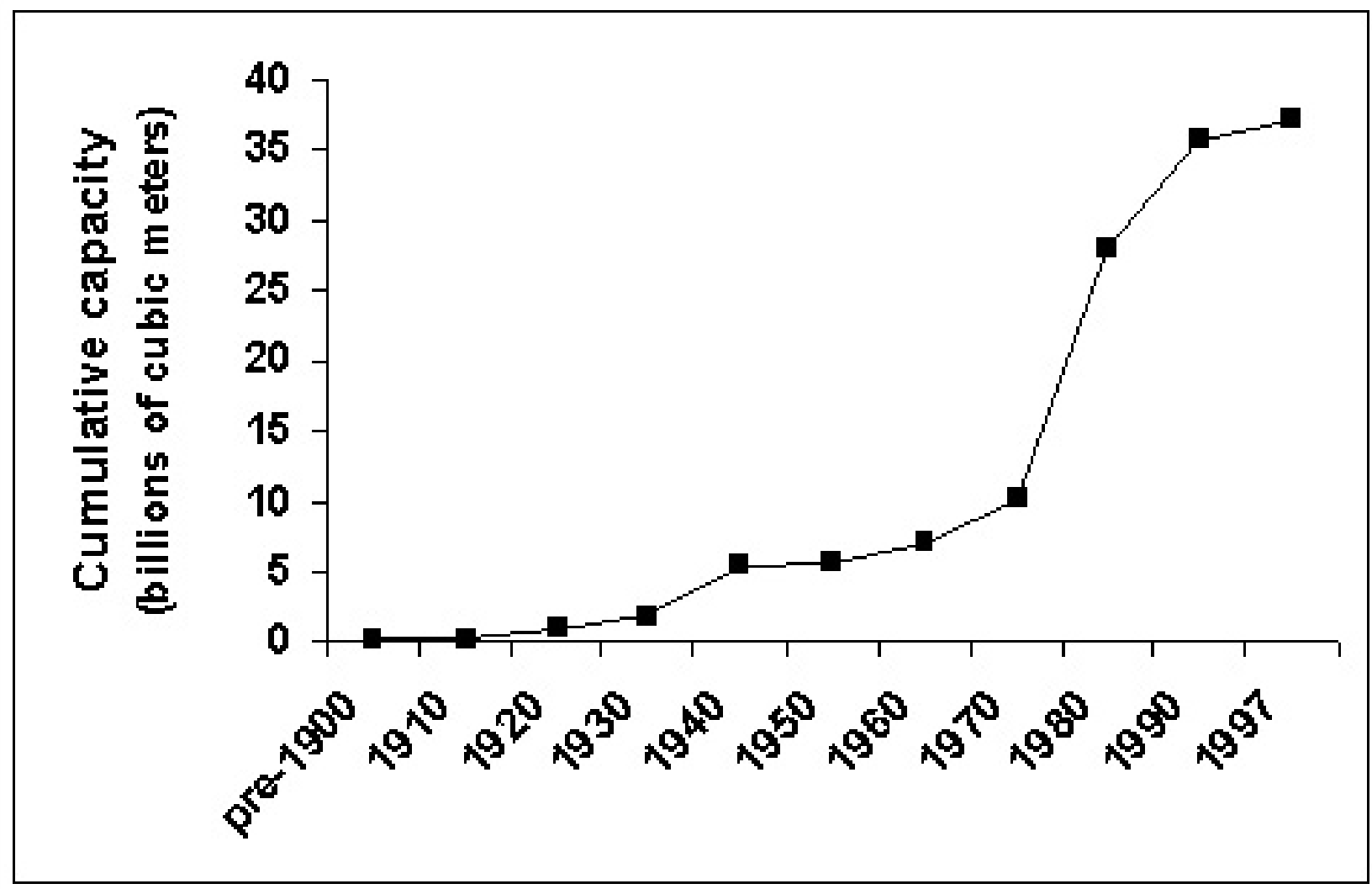


contributions to the collective knowledge base of local communities, which are often the first to detect a problem because they are the closest to it. Communities in the Great Fish River valley of South Africa, for example, have been tacitly monitoring water quality during the past four decades as part of their daily use to determine whether silt levels in runoff from cattle dips are within acceptable limits (Shackleton et al. 2004). However, with no effective means of transmitting this information upward, local knowledge remains in the community and cannot influence the causal processes operating at higher levels.

\section{The "some, for all, forever" era}

In the late 1980s and early 1990s, data became available from South African monitoring programs that revealed the long-term trend of deterioration of water resources and aquatic ecosystems (MacKay 2003). As the limits of the supply augmentation responses of the past were increasingly exposed, the need for a new approach to water allocation became urgent. In 1994, apartheid and minority rule ended in South Africa. The country's transition to democracy presented a unique opportunity to reform its 1956 water policy to better reconcile its resources with the needs of its people, environment, and economy. This marked the onset of a new paradigm in the water sector, in which the emphasis of water provision quite rapidly broadened to encompass the needs of ecosystems and of society in its entirety. Financing for water management was to be achieved by full cost recovery from users rather than from government subsidization. Decision making moved from a technocratic to participatory arena in which pertinent issues could be collectively addressed.

The paradigm shift that occurred as a result of democratic elections and the increased awareness of changes in water quality and quantity was marked by a realignment of the impact, awareness, and power scopes. The power and awareness scopes were brought into greater congruence with the impact scope, providing opportunities to develop effective responses.

The transition from the supply augmentation to the allocation phase has been most apparent in South Africa. Its 1998 Water Act, among the world's most progressive, is founded on the principles of equity, sustainability, and efficiency, and its overarching goal is to provide "some, for all, forever" (MacKay 2003). Noting the needs to redress the inequality of access to water created by past discrimination as well as to provide for future generations, the law promotes equity by its definition of water as a basic human right and guarantees provision of $25 \mathrm{~L} / \mathrm{d}$ of safe water within $200 \mathrm{~m}$ of the home to all South Africans. It promotes sustainability by protecting aquatic ecosystems through ecological reserve requirements, or environmental flows, and resource protection measures. Efficiency is promoted through licensing and pricing strategies designed to allow water to be allocated to the uses of highest value (Department of Water Affairs and Forestry 2002). The water designated for basic human needs and environmental needs defines a legally recognized "reserve" that has the highest allocation priority. Since this law was passed, equity has clearly improved: in 1998,12 x $10^{6}$ people were without any access to formal water services and 21 x $10^{6}$ lacked sanitation (King and Louw 1998). Currently, these numbers have decreased to about $5 \times 10^{6}$ and $16 \times 10^{6}$, respectively, and are steadily dropping (Department of Water Affairs and Forestry 2004).

The equity and sustainability issues highlighted in the South African legislation have also surfaced in the Zambezi, where several of the nations that share this basin are currently reforming their water policies or institutions to incorporate principles of environmental and social sustainability (Scholes and Biggs 2004). The deteriorating state of the Zambezi delta and its wetland ecosystems as a result of the changed flood regime from the two major dams and their implications for the livelihoods of delta inhabitants have led Mozambican and international scientists to negotiate for rehabilitation measures (Beilfuss and Davies 1998). The recent declaration of the delta's Marromeu complex as a Ramsar Site, i.e., a wetland of international importance as defined by the Ramsar Convention on Wetlands, may facilitate the process, although, to a large degree, the many governments managing this basin lack the institutional mechanisms at present to implement the necessary measures.

\section{New institutions for water management}

As water management moved into the allocation phase in South Africa, it became clear that the existing Department of Water Affairs and Forestry (DWAF) and its policies did not support public 
participation in decision making. Rather, the new thinking about water management embraces the idea that natural resources are most effectively managed when responsibility is shared with democratic local institutions, which presumably have detailed and key information about the resources and are more easily held accountable to local populations (Ribot 2002).

The South African Water Act of 1998 mandates the establishment of 19 statutory bodies called catchment management agencies (CMAs) to govern water resources in conjunction with locally elected boards that represent a wide range of stakeholders (Department of Water Affairs and Forestry 2002). Each CMA is responsible for a water management area that corresponds with major catchment boundaries, for which it can license water users and establish charges for different uses of water, the revenues from which will fund the CMA's management activities. The CMA will also be responsible for implementing the appropriate resource protection measures to meet the requirements of the ecological reserve. This decentralizes decision making in the water sector, and, although the national agency, DWAF, remains the custodian of South Africa's water resources and oversees its national strategy, the authority to execute the strategy will increasingly lie with the CMAs and local institutions within the catchment.

It is uncertain at this time if the CMAs, which are to be fully functioning in the next 5-10 yr, will be able to successfully implement the new policies. Few areas within the Gariep basin are expected to have the capacity to carry out their functions in the near term. Of concern is the fact that they are being charged with both the allocation of water and the protection of the resource in their catchments, two not necessarily compatible tasks that were never before administered by a single authority (Rogers et al. 2000). In such a situation, more powerful interests within the CMA may be able to bring the impact and power scopes out of congruence, or, by manipulating information, constrain the awareness of those in the impact scope.

Whether the CMAs will provide a successful mechanism within South Africa's broader legal environment for contesting water use is also unknown. An independent Water Tribunal can hear and adjudicate appeals against certain decisions concerning water allocation, and further appeals can be made to the High Court, although the reserve and some resource protection measures cannot be contested once established (MacKay 2003). The Water Act is designed so that, in principle, one CMA cannot negatively impact the water resources of another, thus securing the needs of downstream catchments. However, the Water Act gives CMAs the authority to manage only surface water and groundwater, whereas activities that occur on land are the jurisdiction of other agencies (MacKay 2003). This may leave room for loopholes in the application of the law and introduces a further source of incongruence between the impact and power scopes. What may be more likely is that power will revert to the centralized model if the CMAs are unable to carry out their functions successfully.

\section{Regional cooperation}

Whereas some functions of water management are being devolved to a finer scale, others are evolving to address the problems that pervade large river basins spanning international boundaries. These issues are frequently rooted in the complexities of hydropolitics (Turton 2002), and thus the comanagement of international river basins usually requires the establishment of bi- or multilateral institutions. Previously, the water security of one nation was often assured by compromising that of another, usually downstream or institutionally weaker, nation. Today, regional institutions for river basin management or river basin organizations (RBOs) are being established on the premise that water insecurity threatens the development capacity and hence political stability of the greater region. Turton (2003) observes that one function of an RBO is to create a convergence of ideas around a common security and reduced uncertainty for all member states. This is largely achieved through the sharing of data, a common set of rules, and a formal agreement for conflict resolution that leads to a broadening and sharing of awareness and power to collectively manage common impacts.

Several legal and institutional frameworks support regional cooperation. The Protocol on Shared Water Course Systems of the South African Development Community (SADC), last revised in 2003 and ratified by all of the Gariep and Zambezi states except Angola, is a legal instrument for achieving the development goals of the water sector. Although the protocol requires that joint management mechanisms be established, it does not explicitly 
suggest how this should be done. Thus, a range of RBOs exists in southern Africa, with each operating under a unique set of rules. In the Gariep basin, the Orange-Senqu River Commission established in 2000 by South Africa, Lesotho, Botswana, and Namibia is intended to provide a forum to discuss technical matters related to the mutually shared resources of the basin states. It does not, however, take precedence over the national legislation of each country or existing bilateral protocols, and is not yet recognized as an established international water management body by the South African Water Act (Department of Water Affairs and Forestry 2002).

The Action Plan for the Environmental Management of the Common Zambezi River System was initiated in 1987 with the support of donor governments, but stalled when it was taken over in 1995 by SADC's new water sector, after which time confusion regarding ownership of the process delayed project preparation. Although a new plan has since been launched with the aim of achieving development objectives based on secure water supplies, local institutions must first establish an enabling environment and build enough capacity to execute the plan (Granit 2000), which is apt to further delay any real action. Despite years of discussion and meetings, the emphasis on cooperation of the agencies managing the Zambezi River has had little apparent effect, even as many warnings of the ecological and social consequences of dam construction that were ignored over the past decades have now come to fruition (Davies et al. 2000).

The barriers faced by RBOs are in some ways similar to those the CMAs may confront. First, power among stakeholders is likely to be asymmetrical because of the great diversity of socioeconomic characteristics and management systems among basin states. States with weak economies and limited capacities to manage water usually have less bargaining power. In addition, there is no guarantee of adherence to those principles of SADC treaties that are not embedded in national laws (South African Research and Documentation Centre 2001), which often differ, sometimes irreconcilably. In these cases, the impact scope has no way to influence the power scope, and the power of the regional institutions is constrained.

The degree to which regional cooperation succeeds may depend on the extent to which a paradigm shift similar to that witnessed in South Africa emerges in the larger southern African region. The negative impacts of the Kariba and Cahora Bassa dams on the delivery of ecosystem services predicted decades ago may eventually motivate a management change in the Zambezi basin that encompasses multiple objectives and stakeholders. What seems clear is that a sustainable course of water management in southern Africa will need to evolve against a backdrop of increasing regional integration. Water resources could potentially serve as an integrating link, through concepts such as "virtual water." In this model, water-intensive commodities such as grain, which requires approximately $1000 \mathrm{~m}^{3}$ of water/t, are produced by countries with low water stress, such as Zambia or Angola, for export to water-scarce countries such as South Africa or Namibia, freeing those countries to allocate their water resources to higher-efficiency uses. As seen in other areas of the world where it occurs (Allan 2002), virtual water trade has significant economic benefits for the importer. However, this model is not yet viable for southern Africa as a region because many countries lack the necessary technical capacity and political stability and are reluctant to relinquish agricultural selfsufficiency and national security to a regional body. The idea of regional cooperation should be to foster collective security while simultaneously giving each member state sufficient flexibility in determining its goals and how to achieve them, thus preserving the variability, and hence the resilience, of the regional water mosaic. This highlights the need for certain elements of regional management to be agreed upon at a regional scale, whereas others must be tailored to unique conditions at as local a scale as appropriate and possible.

As lessons learned from other systems reveal, crises in social-ecological systems often occur at the intersection of large-scale processes and changing local variability, as local problems cascade up to higher levels (Gunderson et al. 2002). This is why institutions at different scales, such as those we describe here, need to communicate and exchange information with one another, especially as southern African people and institutions find themselves responding with increasing frequency to the local effects of novel regional changes in climate, global markets, and political initiatives. Information needs to flow not only from the top to the bottom, but also in the reverse direction. Although the monitoring routinely done by communities can provide important early-warning data, this exchange of information between local and higher-level 
institutions cannot happen if they operate independently, as they have traditionally done. The institutional arrangements that are apt to produce the most effective responses may entail a multisubsidiarity arrangement that allows local organizations, CMAs, RBOs, and national ministries to work collectively toward a common end.

\section{Integrated responses}

Increasingly, the sectoral approach to natural resources management that was taken in the past is being replaced by the adoption of responses that are integrated across ecosystem service sectors. Integrated water resources management is an internationally recognized framework in which policies and practices address the linkages between water, land, and environmental resources through the hydrological cycle (Department of Water Affairs and Forestry 2002).

One of the most notable integrated responses in the region is the Working for Water Programme in South Africa, a multiagency intervention to combat the spread of invasive alien plants, which consume approximately $3300 \times 10^{6} \mathrm{~m}^{3}(7 \%)$ of the country's total mean annual runoff and are expected to become an increasing threat in the future (Le Maitre et al. 2000). By hiring previously unemployed individuals to clear and eradicate invasive alien plants, Working for Water addresses the multiple objectives of water conservation, ecosystem rehabilitation, and poverty relief through job creation and the development of secondary industries from products made from the cleared alien species. Through its high visibility and public campaigns, the program has raised awareness about alien plants and water conservation among its employees, their communities, and a broad spectrum of society, and has stimulated research on invasive alien plants in the scientific and engineering communities (Görgens and van Wilgen 2004).

The Working for Water program had an initial budget of $25 \times 10^{6}$ South African Rands in 19951996, which increased to $442 \times 10^{6}$ South African Rands in 2003-2004 thanks to the program's success over the years (Marais et al. 2004). Although it is currently funded through special poverty relief funds, eventually these costs are intended to be recovered from the water resources management charges imposed on users, as specified by the Water Act. By the end of 2003, the clearing of almost 1.2 $\mathrm{x} 10^{6}$ ha of alien vegetation by the 24,000 people employed by the program was estimated to yield annual water benefits of $50 \times 10^{6}$ to $130 \times 10^{6} \mathrm{~m}^{3}$ (Görgens and van Wilgen 2004). Several costbenefit analyses in South Africa suggest that clearing is a cost-effective approach to eradicating invasive alien plants in terms of water resources (Görgens and van Wilgen 2004), although costs tend to be overestimated and benefits underestimated and highly discounted because they often emerge only in the long term (Turpie 2004).

The Working for Water program is probably the best example of an effective response according to our framework: it empowers and increases the awareness of the impacted population. It also fits our definition of "effective": the program's mechanisms for maintaining social and ecological resilience are mutually reinforcing, because a synergy is created between social development in the form of job creation/poverty relief and the preservation of ecological integrity, i.e., alien eradication, restoration of hydrological flows, and improved production potential of land. By freeing water resources for other uses, the initiative also has the potential to yield significant economic benefits over the longer term.

\section{DISCUSSION}

The congruence of impacts, awareness, and power is at the heart of the "some, for all, forever" concept. This concept is realized through an awareness based on widely distributed cross-sectoral and cross-scale information, power decentralization, and cooperation through the development of new institutions and effective mechanisms for influencing power at different scales. Although our framework suggests that this is indeed the situation most conducive to developing effective responses, our application of the framework to water management in southern Africa reveals several caveats.

First, ecological, economic, and even social processes that relate to impact rarely conform to administrative structures or scales, which relate to power. Some southern African experiments in distributing power, such as Community Based Natural Resource Management, have failed when power is maintained at specific scales (Fabricius et al. 2001). The interactions of cross-scale and cross- 
sectoral institutions come with high transaction costs. Line ministries and managers are accountable to their ministers and agencies first; cooperation is an afterthought. We have noted that the new water management institutions may encounter similar problems.

Second, in some instances, the responses of previous eras severely constrain the response options available for the current era. The hydrological flow regime created by the Cahora Bassa dam over the past few decades has been one of controlled and constant low-level flows. Gone are the huge floods of the past. One consequence of this has been that people have moved into areas of the Zambezi Delta floodplain that formerly would have been safe only for temporary house construction or limited agricultural development. Recent attempts to restore a more natural flood regime for the Zambezi (Beilfuss and Davies 1998) are constrained by the developments on the floodplain, which would require expensive movements of people and infrastructure and could even result in loss of life. In the Gariep basin, the operating costs of the infrastructure built by previous governments deplete funds that could have been invested in demand-side initiatives and the provision of basic services. The list of foregone opportunities is long.

Third, a distribution of power does not necessarily mean a distribution of awareness, although we suspect the latter would follow from the former. Awareness, in a multiscaled system created through power devolution, means a distributed capacity to learn as well as mechanisms to transfer lessons, knowledge, or information across scales. The development of these mechanisms is likely to lag significantly behind power transfers, which tend to follow political time scales. Consequently, responses made in the initial period after a redistribution of power may yield a great range of results, from great successes to abysmal failures. What is most worrying about this is the high turnover in human expertise that now characterizes southern African management agencies. A continued loss of expertise from these agencies, which are a major repository of social memory, could mean long periods of ineffective responses and, possibly, considerable pressure to revert to centralized controls as a consequence, in a decentralization backlash (Ribot 2002).

We thus note a limitation in the application of our framework to complex systems in the real world: it can be extremely difficult to achieve congruence between impact, awareness, and power because it goes against the grain of social-ecological system structure. The scales at which impact, awareness, and power operate are mismatched in space and time. Bearing this in mind, however, the framework points to several features of responses that are likely to increase their effectiveness if incorporated into their design.

\section{Designing effective responses}

Our analysis suggests that effective responses in complex adaptive systems are characterized by the following factors:

Congruence between the scopes of impacts, awareness, and power. We acknowledge that this may be difficult and is beyond people's control in many situations. In cases where people cannot affect the indirect drivers of an impact, they may still be able to adopt proactive response options. For example, local livelihood diversification is a coping strategy to deal with uncertainty (Shackleton et al. 2004). At national scales, governments often cannot affect drivers of global processes like climate change; however, they can be proactive by preparing for uncertainty and managing ecosystem services with the possible range of extreme conditions in mind. Often, a response is both a consequence of the responses that came before and a driver of the responses that will come after. When and where congruence already exists, it needs to be maintained through the continued implementation of effective responses. New responses must try to establish the best conditions for future responses to take shape.

Distribution of impacts, awareness, and power across locations in space and time. Different social groups or ecological groups or locations are differentially vulnerable to change. The most effective responses will be those that differentiate between these groups, or, where this cannot be done, provide different response options for them. Suggested flow regime changes for the Zambezi River downstream of the Cahora Bassa dam, for example, seek to do this with releases from the dam geared to continued hydroelectricity generation as well as the maintenance of the downstream ecosystem services on which local livelihoods depend. Awareness, too, needs to be effectively 
distributed by feeding cross-sectoral and cross-scale information and knowledge into decision-making processes.

Expansion of response options at and across all scales. The ability to respond meaningfully to change is greatly enhanced if we have a large set of responses to choose from. Effective responses may be generated more successfully by expanding people's response options rather than by direct interventions. If we accept that we can never know enough about any complex system to fully control it, then the wisest course of action may be to let the impacted themselves make choices from the widest possible set of options. The process of involving a wide range of stakeholders in ecological reserve determinations, as suggested by the South African Water Act, is an example of how this can be done.

Enhanced or stabilized social memory. One of the gravest problems of management and policy in southern Africa is the constant loss of human capital from the agencies most intimately involved in implementing responses. Long-term experts are lost to the private sector, to international nongovernmental organizations, and to distant continents. Local ecological knowledge is lost as rural people move to cities and become disconnected from the cultures in which the knowledge is embedded. Moving with many of these people are their experiences in response experimentation, i.e., key bits of social memory. There does not seem to be a simple solution to this problem other than to create stronger incentives for them to stay. Orderly documentation of their experiences does not always seem to work. Loss of documents and records or the inability to accept recommendations because of a lack of experience means that important lessons that should have been learned are sometimes not. This may be an area that requires special research attention: how do we maintain social memory in the face of very fluid human capital?

\section{CONCLUSIONS}

What factors characterize effective responses in complex adaptive systems? We have defined "effective" responses as those that maintain the social and ecological resilience, or the ability to withstand change, of a complex system. Drawing on the experience of the Southern African Millennium Ecosystem Assessment (SAfMA), we crafted a simple framework to evaluate responses consisting of three components: impact, awareness, and power. We have suggested that effective responses are those in which (1) the scopes of impact, awareness, and power are congruent; (2) impact, awareness, and power are distributed across the system; (3) broad response options are available; and (4) social memory is preserved. In applying this framework to a range of responses for managing water in southern Africa, we observed that it may be extremely difficult to achieve or maintain congruence. Responses are adaptive reflections of prevailing social, economic, political, and ecological conditions. This explains in part the SAfMA team's difficulty in assessing and extracting meaningful lessons from the responses of the past. Responses are constructed and implemented in specific contexts. When these contexts change, as they invariably do, we should expect responses to change too, possibly rendering the responses that are effective now useless in the future. No two situations are ever the same, and we should therefore be surprised if they elicit the same responses. A government's response to the construction of a major dam when it approaches an election may be entirely different than it would be when it has a major drought on its hands. Not only are responses and their contexts dynamic, but the particular lens through which we view and evaluate the world is also dynamic because of changing social objectives. Responses in the era of "get more water" were consistent with a defined set of social objectives. This set has now been swept offstage and replaced with an updated version.

By examining the two different trajectories of the Gariep and Zambezi with our framework, we can apply our learning about responses from one to the other, although with the understanding that water management is operating within a different context now than it was during the early development phases of these basins. Water is increasingly being seen in southern Africa as a regional resource, presenting opportunities for a redefinition of impact, awareness, and power scopes. As the region becomes more interconnected through its water resources, opportunities for learning are expanded.

Responses to changing relationships between ecosystem services and human well-being require constant adjustment and adaptation. We adapt our responses to the prevailing circumstances and add the experience to our memory. We learn. Responses to changes in complex adaptive systems are complex adaptive systems themselves. Given that 
we cannot predict what a complex system will do, we are unlikely to be able to design responses that will steer the system to where we want it to be. At best, effective responses should provide incentives for a complex system to remain within desirable configurations.

The framework provides a useful tool for exploring the problem of responding in complex systems and could be used in other applications beyond those discussed here. Although we looked backward in this paper by evaluating the historical trajectory of water management responses in southern Africa, our evaluation would be likely to benefit from further development in conjunction with scenario analysis. Scenarios provide a wind tunnel for envisioning alternative future worlds, and can help people to identify the response options that are most likely to be robust, i.e., enhance resilience, in the different futures that may unfold.

Responses to this article can be read online at: http://www.ecologyandsociety.org/vollo/iss 1/art11/responses/

\section{Acknowledgments:}

We thank the Gariep Basin and GorongosaMarromeu User Advisory Groups for providing data and insights for the assessments. Members of SAfMA, particularly R. Biggs, contributed ideas for this paper, an early version of which was presented at "Bridging Scales and Epistemologies: Linking Local Knowledge with Global Science in MultiScale Assessments," in Alexandria, Egypt, in March 2004. D. Biggs and J. Jones read the manuscript and made helpful suggestions. Funding for SAfMA was provided by the Millennium Ecosystem Assessment through a grant from the government of Norway, administered by the United Nations Environment Programme.

\section{LITERATURE CITED}

Allan, T. 2002. Water resources in semi-arid regions: real deficits and economically invisible and politically silent solutions. Pages 23-36 in A. R. Turton and R. Henwood, editors. Hydropolitics in the developing world: a southern African perspective. African Water Issues Research Unit, Pretoria, South Africa.

Aquatic Resource Management for Local Communities (ALCOM). 1999. Database of South African water bodies, source, content and data structure. ALCOM Working Paper 18. ALCOM, Lusaka, Zambia.

Beilfuss, R., and B. R. Davies. 1998. Prescribed flooding and the rehabilitation of the Zambezi Delta. Pages 143-158 in W. J. Streever, editor. International perspectives on wetland rehabilitation. Kluwer, Dordrecht, The Netherlands.

Biggs, R., E. Bohensky, P. V. Desanker, C. Fabricius, T. Lynam, A. A. Misslehorn, C. Musvoto, M. Mutale, B. Reyers, R. J. Scholes, S. Shikongo, and A. S. van Jaarsveld. 2004. Nature supporting people: The Southern African Millennium Ecosystem Assessment. CSIR, Pretoria, South Africa.

Carpenter, S., B. Walker, J. M. Anderies, and N. Abel. 2001. From metaphor to measurement: resilience of what to what? Ecosystems 4: 765-781.

Chutter, F. M., R. W. Palmer, and J. J. Walmsley. 1996. Environmental overview of the Orange River. Orange River Development Project Replanning Study, DWAF report PD 00/00/5295. Department of Water Affairs and Forestry, Pretoria, South Africa.

Costanza, R., L. Wainger, C. Folke, and K.-G. Mäler. 1993. Modeling complex ecological economic systems: toward an evolutionary, dynamic understanding of people and nature. BioScience 43(8):545-555.

Davies, B. R., R. D. Beilfuss, and M. C. Thoms. 2000. Cahora Bassa retrospective, 1974-1997: effects of flow regulation on the Lower Zambezi River. Limnology in the Developing World 27:1-9.

Dent, M. C. 2000. Strategic issues in modelling for integrated water resource management in southern Africa. Water SA 26(4):513-519.

Department of Water Affairs and Forestry (DWAF). 2002. Proposed first edition of the National Water Resources Strategy. DWAF, Pretoria, South Africa. Available online at: http://www.dwaf.gov.za/Documents/Policies/NWRS/ 
main.htm.

Department of Water Affairs and Forestry (DWAF). 2004. A decade of delivery. DWAF, Pretoria, South Africa. Available online at:

http://www.dwaf.gov.za/Communications/Articles/ Kasrils/2004/TEN\%20YEARS\%200F\%20DELIVER\% 20ARTICLE.doc.

Fabricius, C., E. Koch, and H. Magome. 2001. Community wildlife management in southern Africa: challenging the assumptions of Eden. Evaluating Eden Series, Number 6. International Institute for Environment and Development, London, UK.

Falkenmark, M., and C. Widstrand. 1992. Population and water resources: a delicate balance. Population Bulletin. Population Reference Bureau, Washington, D.C., USA.

Görgens, A. H. M., and B. W. van Wilgen. 2004. Invasive alien plants and water resources in South Africa: current understanding, predictive ability and research challenges. South African Journal of Science 100:27-33.

Granit, J. 2000. Management of shared water resources in Southern Africa and the role of external assistance. First WARFSA/WaterNet Symposium: Sustainable Use of Water Resources (Maputo, Mozambique, 2000). Available online at: http://www.iwsd.co.zw/Papers\%5CGranit.pdf.

Gunderson, L. H., and C. S. Holling, editors. 2002. Panarchy: understanding transformations in human and natural systems. Island Press, Washington, D.C., USA.

Gunderson, L. H., C. S. Holling, and G. D. Peterson. 2002. Surprises and sustainability: cycles of renewal in the everglades. Pages 315-332 in L. H. Gunderson and C. S. Holling, editors. Panarchy: understanding transformations in human and natural systems. Island Press, Washington, D.C., USA.

Herold, C. E. 1992. Increasing awareness of water quality imperatives. Stewart Scott Inc., Sandton, South Africa.

Holling, C. S., and L. H. Gunderson. 2002. Resilience and adaptive cycles. Pages 25-62 in L. H. Gunderson and C. S. Holling, editors. Panarchy: understanding transformations in human and natural systems. Island Press, Washington, D.C., USA.

Isaacman, A., and C. Sneddon. 2000. Toward a social and environmental history of the building of Cahora Bassa dam. Journal of Southern African Studies 26(4):597-632.

Jones, P. G., and P. K. Thornton. 2003. The potential impacts of climate change on maize production in Africa and Latin America in 2055. Global Environmental Change 13(1):51-59.

Johannes, R. E. 1998. The case for data-less marine resource management: examples from tropical nearshore fisheries. Trends in Ecology and Evolution 13:243-246.

King, J., and D. Louw. 1998. Instream flow assessments for regulated rivers in South Africa using the Building Block Methodology. Aquatic Ecosystem Health and Management 1:109-124.

Klasen, S. 2002. The costs and benefits of changing in-stream flow requirements (IFR) below the Phase 1 structures of the Lesotho Highlands Water Project. Lesotho Highlands Development Authority, Maseru, Lesotho. Available online at: http://www.tcta.co.za/LHWP/econ Klasen.PDF.

Le Maitre, D. C, D. B. Versveld, and R. A. Chapman. 2000. The impact of invading alien plants on surface water resources in South Africa: a preliminary assessment. Water SA 26(3):397-408.

Lee, K. N. 1993. Compass and gyroscope: integrating science and politics for the environment. Island Press, Washington, D.C., USA.

Lesotho Highlands Development Authority (LHDA). 2002. Lesotho Highlands Water Project Phase I IFR Policy. LHDA, Maseru, Lesotho. Available online at

http://www.lhwp.org.ls/downloads/policies/APPROVED\% 20IFR\%20POLICY\%2013-12-02.htm.

Lynam, T., B. Reichelt, R. Owen, A. Sitoe, R. Cunliffe, and R. Zolho. 2004. Human well-being and ecosystem services: an assessment of their linkages in the Gorongosa-Marromeu region of Sofala Province, Mozambique to 2015. Southern African Research and Documentation Centre, Harare, Zimbabwe. 
MacKay, H. M. 2003. Water policies and practices. Pages 49-83 in D. Reed and M. de Wit, editors. Towards a just South Africa: the political economy of natural resource wealth. World Wildlife Fund Macroeconomics Programme Office, Washington, D.C., USA, and CSIR, Pretoria, South Africa.

Marais, C., B. W. van Wilgen, and D. Stevens. 2004. The clearing of invasive alien plants in South Africa: a preliminary assessment of costs and progress. South African Journal of Science 100:97-103.

Millennium Ecosystem Assessment. 2003. Ecosystems and human well-being: a framework for assessment. Island Press, Washington, D.C., USA.

Molle, F. 2003. Development trajectories of river basins: a conceptual framework. Research Report 72. International Water Management Institute, Colombo, Sri Lanka.

Motteux, N. M. G. 2002. Evaluating peopleenvironment relationships: developing appropriate research methodologies for sustainable management and rehabilitation of riverine areas by communities in the Kat River Valley, Eastern Cape Province, South Africa. Dissertation. Rhodes University, Grahamstown, South Africa.

Ohlsson, L., and A. R. Turton. 2000. The turning of a screw: social resource scarcity as a bottle-neck in adaptation to water scarcity. Stockholm Water Front 1:10-11

Revenga, C., S. Murray, J. Abramovitz, and A. Hammond. 1998. Watersheds of the world: an assessment of the ecological value and vulnerability of the world's watersheds. World Resources Institute, Washington, D.C., USA.

Ribot, J. C. 2002. Democratic decentralization of natural resources: institutionalizing popular participation. World Resources Institute, Washington, D.C., USA.

Rogers, K., D. Roux, and H. Biggs. 2000. Challenges for catchment management agencies: lessons from bureaucracies, business and resource management. Water SA 26(4):505-511.

Scholes, R. J., and R. Biggs. 2004. Ecosystem services in southern Africa: a regional assessment.
CSIR, Pretoria, South Africa.

Shackleton, C., C. Fabricius, A. Ainslie, G. Cundill, H. Hendricks, S. Matela, and N. Mhlanga. 2004. Southern African Millennium Assessment: Gariep Basin Local Scale Assessments. Rhodes University, Grahamstown, South Africa.

Snaddon, C. D., B. R. Davies, and M. J. Wishart. 1999. A global overview of inter-basin water transfer schemes, with an appraisal of their ecological, socio-economic and socio-political implications, and recommendations for their management. Water Research Commission Technology Transfer Report TT 120/00. Water Research Commission, Pretoria, South Africa.

Snaddon, C. D., M. J. Wishart, and B. R. Davies. 1998. Some implications of inter-basin water transfers for river ecosystem functioning and water resources management in southern Africa. Journal of Aquatic Ecosystem Health and Management 1:159-162.

Soils Incorporated (Pty) Ltd and Chalo Environmental and Sustainable Development Consultants. 2000. Kariba Dam Case Study, prepared as an input to the World Commission on Dams, Cape Town, South Africa. Available online at: http://www.dams.org.

Southern African Research and Documentation Centre (SARDC). 2001. Development in southern Africa: a sectoral review of regional integration in $S A D C$. Regional Economic Development and Integration Programme of the Southern African Research and Documentation Centre, Harare, Zimbabwe.

Thabane, M. 2000. Shifts from old to new social and ecological environments in the Lesotho highlands water scheme; relocating residents of the Mohale dam area. Journal of Southern African Studies 26(4):633-654.

Turpie, J. 2004. The role of resource economics in the control of invasive alien plants in South Africa. South African Journal of Science 100:87-93.

Turton, A. R. 2002. Hydropolitics: the concept and its limitations. Pages 13-22 in A. R. Turton and R. Henwood, editors. Hydropolitics in the developing world: a southern African perspective. African Water Issues Research Unit, Pretoria, South Africa. 
Turton, A. R. 2003. The hydropolitical dynamics of cooperation in southern Africa: a strategic perspective on institutional development in international river basins. African Water Issues Research Unit, Pretoria, South Africa.

United Nations Development Programme (UNDP). 2003. Human Development Report 2003. UNDP, New York, New York, USA.

World Commission on Dams. 2000a. Dams and development: a new framework for decisionmaking. Earthscan Publications, London, UK, and Sterling, Virginia, USA. Available online at:

http://www.dams.org.

World Commission on Dams. 2000b. Orange River Development Project, South Africa case study, prepared as an input to the World Commission on Dams, Cape Town, South Africa. Available online at: http://www.dams.org. 